\title{
Monitoring Grape Berry Moth (Paralobesia viteana: Lepidoptera) in Commercial Vineyards using a Host Plant Based Synthetic Lure
}

\author{
GREGORY M. LOEB,${ }^{1,4,5}$ DONG H. CHA, ${ }^{1}$ STEPHEN P. HESLER, ${ }^{1}$ CHARLES E. LINN, JR., ${ }^{1}$ \\ AIJUN ZHANG, ${ }^{2}$ PETER E. A. TEAL, ${ }^{3}$ AND WENDELL L. ROELOFS ${ }^{1}$
}

\begin{abstract}
Environ. Entomol. 40(6): 1511-1522 (2011); DOI: http://dx.doi.org/10.1603/EN10249
ABSTRACT For some Lepidopteran pests, such as the grape berry moth Paralobesia viteana (Clemens), poor correlation between males captured in traps baited with sex pheromone and oviposition activities of female moths has called into question the value of pheromone-based monitoring for these species. As an alternative, we compared the capture of female and male grape berry moth in panel traps baited with synthetic host volatiles with captures of males in pheromone-baited wing traps over two growing seasons in two blocks of grapes in a commercial vineyard in central New York. Lures formulated in hexane to release either 7-component or 13-component host volatile blends captured significantly more male and female grape berry moth on panel traps compared with the numbers captured on panel traps with hexane-only lures. For both sexes over both years, the same or more moths were captured in panel traps along the forest edge compared with the vineyard edge early in the season but this pattern was reversed by mid-season. Male moths captured in pheromone-baited wing traps also displayed this temporal shift in location. There was a significant positive correlation between captured males and females on panel traps although not between females captured on panel traps and males captured in pheromone-baited traps for both years suggesting pheromone traps do not accurately reflect either female or male activity. Male moths captured in pheromone traps indicated a large peak early in each season corresponding to first flight followed by lower and variable numbers that did not clearly indicate second and third flights. Panel trap data, combining males and females, indicated three distinct flights, with some overlap between the second and third flights. Peak numbers of moths captured on panel traps matched well with predictions of a temperature-based phenology model, especially in 2008. Although effective, panel traps baited with synthetic host lures were time consuming to deploy and maintain and captured relatively few moths making them impractical, in the current design, for commercial purposes.
\end{abstract}

KEY WORDS phenology, Tortricidae, volatiles, spatial distribution, population

Over the past $40 \mathrm{yr}$ there has been a wealth of research on insect pheromones and their use in pest management including monitoring flight activity, attract and kill devices, and mating disruption (Ridgway et al. 1990, Rodriguez-Saona and Stelinski 2009). The use of pheromones for monitoring pest phenology is an important part of many integrated pest management (IPM) programs, but their effectiveness varies depending on the system and the type of information that is sought (Wall 1990). Captures of male moths in traps baited with synthetic sex pheromone can provide information on presence of a species in an area, insect phenology, and in a few cases, also pest density

\footnotetext{
${ }^{1}$ Department of Entomology, New York State Agricultural Experiment Station, Cornell University.

${ }_{2}^{2}$ USDA-ARS-PSI, Invasive Insect Biocontrol and Behavior Laboratory, Beltsville, MD 20705.

${ }^{3}$ USDA-ARS, Chemistry Research Unit, Center for Medical, Agricultural, and Veterinary Entomology, Gainesville, FL 32608.

${ }^{4}$ Department of Entomology, New York State Agricultural Experiment Station, Cornell University. Geneva, NY 14456.

${ }^{5}$ Corresponding author, e-mail: gmel@cornell.edu.
}

(Wall 1990). However, the reliability and usefulness of pheromone-baited traps varies among different Lepidopteran species based on how well trap captures of males correspond to female activity and damage (Wall 1990, Howse et al. 1998). At their most useful, monitoring traps can help predict risk of crop damage and whether damage will exceed thresholds (Shelton and Wyman 1979, Tingle and Mitchell 1981, Ramaswamy et al. 1983, Van Steenwyk et al. 1983, Morewood et al. 2000). More commonly, pheromone traps can be useful for providing a biofix on the first flight of a pest moth in which developmental models can then be used to predict timing of egg-laying and larval eclosion for subsequent generations (Riedl et al. 1976, Vickers and Rothschild 1991, Hoffman et al. 1992, Li and Fitzpatrick 1997). However, considerable variation can exist in the relationship between trap catch of males and timing of egg-laying from site to site and from year to year, especially for multivoltine species (Alford et al. 1979, Glen and Brian 1982, Hoffman 1990).

Grape berry moth Paralobesia viteana (Clemens) is widely distributed in North America east of the Rocky 
Mountains (Gleissner 1943, Taschenberg 1945). Overwintered pupae eclose in the spring (May to June), mate, and initiate the first summer generation $(\mathrm{Lu}-$ ciani 1987, Nagarkatti et al. 2001). Eggs of the first generation are laid on flower clusters or young berries of both wild and cultivated grapes (Taschenberg 1945, Hoffman 1990). In the northeastern United States grape berry moth is reported to go through 2-3 generations during the season (Gleissner and Worthley 1941, Gleissner 1943, Hoffman 1990), although in recent years a fourth generation has been observed. Lower and upper developmental thresholds have recently been determined in the laboratory and used for modeling grape berry moth phenology (Tobin et al. 2001).

The sex pheromone of grape berry moth was identified a number of years ago and pheromone-baited traps have been used to monitor flight activity of male grape berry moth (Roelofs et al. 1971, Hoffman and Dennehy 1989, Witzgall et al. 2000). Flight activity in the spring appears to correlate relatively well with female activity and the onset of first generation larvae. Beyond the first flight, however, the correlation between males captured in pheromone traps and egglaying activity and damage is often poor (Hoffman et al. 1992, Botero-Garcés and Isaacs 2003, Teixeira et al. 2009). Hence, pheromone-baited traps have not been particularly useful for predicting the onset of second and later-season generations of grape berry moth.

Given the limitations of pheromone trap capture data in grape berry moth pest management programs there has been considerable interest in developing efficient and reliable traps for female moths. Female moths often use plant odors to locate food and oviposition sites (Visser 1986, Ramaswamy 1988), and these cues may be used as attractants for monitoring purposes (Metcalf and Metcalf 1992, Cossé et al. 1994, Landolt 2000, Light et al. 2001, Trimble and El-Sayed 2005, Ioriatti et al. 2003, Natale et al. 2003; Hern and Dorn 2004; Knight and Light 2005a,b; Bengtsson et al. 2006; Schmidt et al. 2007). Based on wind tunnel assays, we showed that GRAPE BERRY MOTH females use volatiles produced from foliage and shoots to locate grape hosts for oviposition (Cha et al. 2008a). Of the many volatile compounds produced by grape tissue, 11 common plant volatiles [ $(Z)-3$-hexen-1-yl acetate, $(Z)$-linalool oxide, $(E)$ - linalool oxide, nonanal, linalool, (E)-4,8-dimethyl-1,3,7-nonatriene, methyl salicylate, decanal, $\beta$-caryophyllene, germacrene-D, and $\alpha$-farnesene] were initially identified using GCEAD and GC-MS analytical tools. Further investigation revealed a full 13-component blend (Table 1) and two different 7-component blends that resulted in high levels of upwind orientation equivalent to live shoots in wind tunnel bioassays (Cha et al. 2008b).

In an initial field trial conducted in a commercial vineyard late in the field season, traps baited with either the 13-component blend or one of the 7-component blends captured more female grape berry moth than control traps (Cha et al. 2008b). In the current study, we evaluated trap captures of grape berry moth for traps baited with host plant-based lures
Table 1. Relative amounts of volatile compounds for lures used in the field trapping experiments conducted in 2008 (13-component and 7-component lures) and 2009 (7-component lure) in two vineyard plantings in central New York

\begin{tabular}{lcc}
\hline \hline \multicolumn{1}{c}{ Compounds } & $\begin{array}{c}\text { \% } \begin{array}{c}\text { 13-component } \\
\text { lure }\end{array} \\
\text { (E) \& (Z)-linalool oxides }\end{array}$ & $\begin{array}{c}\text { \% 7-component } \\
\text { lure }\end{array}$ \\
nonanal & 4 & 7 \\
$(E)$-4,8-dimethyl-1,3,7- & 9 & 13 \\
$\quad$ nonatriene & 22 & 33 \\
decanal & 18 & 27 \\
germacrene D & 12 & 17 \\
$\beta$-caryophyllene & 2 & 3 \\
(-)-limonene oxide & 4 & \\
n-undecylaldehyde & 7 & \\
(E)-2-decenal & 7 & \\
(-)-limonene & 4 & \\
n-dodecyl aldehyde & 7 & \\
linalyl aldehyde & 4 & \\
\hline
\end{tabular}

See text for loading rates of lures and method of deployment.

or sex pheromone over two field seasons in two blocks of grapes in a commercial vineyard in New York. We specifically addressed four objectives:

1. Determine whether traps baited with host plantbased lures capture more female and male grape berry moth than control traps over two full field seasons.

2. Compare the pattern of capture of female and male grape berry moth in host plant baited traps and male captures in pheromone traps with respect to location (forest edge or vineyard edge) and time of season.

3. Measure the relationship between the capture of female and male grape berry moth in traps baited with host plant-based lures with males captured in pheromone traps.

4. Compare how well captures of moths in host plantbased traps and pheromone traps reflect generation peaks of grape berry moth.

\section{Methods}

Study Sites. We monitored grape berry moth adults at two nearby blocks of grapes at a commercial vineyard in the Finger Lakes region of central New York, during the 2008 and 2009 field seasons. One block of juice grapes (cultivar 'Niagara', Vitis labrusca L.) and referred hereafter as the Niagara site $(5.25 \mathrm{ha}$, total area), was planted along the east side of a narrow, wooded, riparian zone that runs North and South (42.43554 N, $77.13178 \mathrm{~W})$, whereas the second site, planted with the $V$. vinifera interspecific hybrid wine grape Cayuga White, and referred to hereafter as the Cayuga White site (2.5 ha, total area), was located $\approx 0.25 \mathrm{~km}$ to the North, on the west side of the same wooded zone (42.44039 N, 77.13226 W). grape berry moth damage is often more severe along vineyard edges near forests (Hoffman and Dennehy 1989, Trimble et al. 1991, Botero-Garcés and Isaacs 2003) and these sites had a previous history of moderate to high grape berry moth populations. Conventional pro- 
duction practices were followed for these blocks of grapes with the exception that no insecticides were applied during the time of this study.

Traps. We used a custom-made plastic panel trap modified after Knight (2000) for evaluating the hostplant based lures. This is the same design as used by Cha et al. (2008b). Briefly, the panel trap is constructed by overlaying multiple layers of plastic sheets (30 cm by $30 \mathrm{~cm}$; Kittrich Co., LA Mirada, CA) with each sheet coated with STP Oil Treatment. Six holes $(2.5$ by $2.5 \mathrm{~cm})$ were made into each trap (three on top and three on bottom), with a $10 \mathrm{~mm}$-diameter white rubber septum (Kimble Chase LLC, NJ) attached at each hole with a metal pin inserted through the middle plastic layer and woven back out again in manner that placed the pin in the center of each hole. Each set of plastic sheets was attached to a $4 \mathrm{~cm} \times 32 \mathrm{~cm}$ piece of wood using two binder clamps with wire attached to holes in the binder clamps to make a hoop. Each week one layer of plastic was removed from each side of the panel trap thereby exposing clean sheets. New sets of plastic sheets were installed as necessary during the season. A Bio-lure Scenturion delta trap (Suterra LLC, Bend, OR), with a sticky insert for the trap bottom, was used to evaluate grape berry moth sex pheromone lures. A 8-mm red rubber septa (Thomas Scientific, Swedesboro, NJ), loaded with $100 \mu \mathrm{g}$ of the 2-component sex pheromone blend of $(Z)$-9-dodecenyl acetate and $(Z)$-11-tetradecenyl acetate (9:1 ratio) in Geneva, NY, was attached by a pin inserted through the top, in the middle of the trap. Sticky inserts were replaced as needed. All the lures were allowed to dry for $1 \mathrm{~h}$ to minimize the amount of solvent residue in the rubber septa.

Field Experiment, 2008. Panel traps were deployed at the Cayuga White and Niagara sites starting in May 2008. Traps were assigned to one of three treatments: 1) 13-component synthetic host plant blend mixed in hexane, 2) 7-component synthetic blend mixed in hexane and 3) hexane control (Table 1). For traps with synthetic host plant-based lures, a relatively low dose was used for the top three septa (13-C blend = $168.5 \mu \mathrm{g} /$ septa, $7-\mathrm{C}$ blend $=112.5 \mu \mathrm{g})$ and a relatively high dose (13-Cblend $=337.5 \mu \mathrm{g}, 7-\mathrm{Cblend}=225 \mu \mathrm{g}$ ) was used for the bottom three. The two different doses are within the range of doses that female grape berry moth is attracted to in the flight tunnel (Cha et al. 2011). The high concentration lure was expected to stay attractive longer than the low concentration lure in the field. However, based on flight tunnel observations, it was also possible that these lures would be too strong initially under field conditions and deter moths. We reasoned the lower concentration lures would not be as initially repellent. Putting the stronger lures on the bottom of the trap was arbitrary. For control traps, the rubber septa were loaded with 300 $\mu$ of hexane. Each treatment was replicated three times per site along the forest edge adjacent to the vineyard in three blocks and in the vineyard edge in three blocks for a total of six replicates per site per treatment (three in forest edge, three in vineyard), with traps placed at least $10 \mathrm{~m}$ apart. Panel traps installed in forest edge were hung from tree branches at 1-2 $\mathrm{m}$ height while panel traps in vineyards were hung from the top trellis wire at $1.5 \mathrm{~m}$. Pheromone traps were also deployed along the forest edge and vineyard edge at each site, with three traps per location for a total of six traps per site. Pheromone traps were hung at similar heights as panel traps with at least $10 \mathrm{~m}$ separation between pheromone traps or panel traps. Vegetation was cleared away from the immediate vicinity of trap surfaces during the season. Host plant and pheromone lures were replaced approximately every month.

Traps were checked for moths three to five times per week starting in May and ending in the middle of September. At each visit captured moths were removed from the exterior plastic sheets and placed in marked vials and returned to the lab to confirm identification, and to determine sex, based on shape of antennae, abdomen and genitalia, and mating status of females using a dissecting scope. Mating status determination was based on the size and shape of the bursa copulatrix. For pheromone traps, the number of male grape berry moths was determined at each visit and the moths removed from the sticky insert.

Field Experiment, 2009. A similar experimental plan was used in 2009 as in 2008 with the following changes. Rather than two different host plant-based synthetic lures, we used only the 7-Component blend in 2009 compared with control traps with hexaneloaded septa $(300 \mu \mathrm{l})$ (Table 1$)$. For the 7-component lure, the low release rate was $112.5 \mu \mathrm{g} / \mathrm{septa}$ and high release rate was double this amount. Total replication per treatment was the same between the two years. The number of pheromone traps deployed was reduced from six traps per site (three in forest edge, three in vineyard) to four traps per site (two in forest edge, two in vineyard) in 2009.

Statistical Analyses. Mixed model analysis of variance (ANOVA) with repeated measures was used to analyze the effect of host plant-based lure, location (forest edge or vineyard edge), site, block and season on captures of male and female moths on panel traps with trap number as the repeated subject with autoregressive order one covariance structure (Proc Mixed, SAS version 9.2, SAS Institute). Season was defined according to three time periods, early (May to the end of June), mid (July), and late (August to early September), that approximately match the timing of three generations of grape berry moth during the season. Mixed model ANOVA with repeated measures was also used to analyze the effect of location, site, and season for male grape berry moth captured in pheromone traps. The effects of linear combinations of independent variables were compared using contrast statements in SAS Proc Mixed (Littell et al. 1996). For each seasonal category, we summed the total number of moths captured per trap over that time interval. The relationship between males and females captured on panel traps and the relationship between males captured in pheromone traps and females and males captured on panel traps was evaluated through regression, using total number of captured moths per week, 
Table 2. Mixed model repeated measures ANOVA results for total no. of females (mated and unmated) collected on panel traps at two vineyard plantings in central New York for 2008 and 2009 as affected by Site, Location (forest edge, vineyard edge), Lure (control, 7-C blend, 13 -C blend in 2008, control and 7-C blend in 2009), Season (early, middle or late) and interactions

\begin{tabular}{|c|c|c|c|c|c|c|c|c|}
\hline \multirow{2}{*}{ Effect } & \multicolumn{4}{|c|}{2008} & \multicolumn{4}{|c|}{2009} \\
\hline & Num DF & Den DF & $\mathrm{F}$ & $\mathrm{P}$ & Num DF & Den DF & $\mathrm{F}$ & $\mathrm{P}$ \\
\hline Site & 1 & 7.69 & 2.02 & 0.195 & 1 & 10.7 & 4.30 & 0.063 \\
\hline Location & 1 & 7.69 & 7.20 & 0.029 & 1 & 10.7 & 29.32 & $<0.001$ \\
\hline Lure & 2 & 23.8 & 3.57 & 0.044 & 1 & 17.0 & 28.53 & $<0.001$ \\
\hline Lure*location & 2 & 23.8 & 1.58 & 0.227 & 1 & 17.0 & 9.98 & 0.006 \\
\hline Site*location & 1 & 7.69 & 1.40 & 0.272 & 1 & 10.7 & 3.89 & 0.075 \\
\hline Site*lure & 2 & 23.8 & 0.68 & 0.518 & 1 & 17.0 & 0.56 & 0.465 \\
\hline Lure*site*location & 2 & 23.8 & 0.25 & 0.781 & 1 & 17.0 & 0.74 & 0.401 \\
\hline Season & 2 & 51.9 & 5.46 & 0.007 & 2 & 51.5 & 48.12 & $<0.001$ \\
\hline Season*site & 2 & 51.9 & 4.73 & 0.013 & 2 & 51.5 & 1.15 & 0.325 \\
\hline Season*location & 2 & 51.9 & 9.68 & $<0.001$ & 2 & 51.5 & 43.73 & $<0.001$ \\
\hline Season*lure & 4 & 53.4 & 0.62 & 0.648 & 2 & 51.5 & 12.88 & $<0.001$ \\
\hline Season*site*location & 2 & 51.9 & 4.88 & 0.011 & 2 & 51.5 & 2.39 & 0.102 \\
\hline Season*lure*location & 4 & 53.4 & 1.86 & 0.131 & 2 & 51.5 & 13.51 & $<0.001$ \\
\hline Season*lure*site & 4 & 53.4 & 0.12 & 0.974 & 2 & 51.5 & 0.49 & 0.613 \\
\hline Season*lure*site*location & 4 & 53.4 & 0.40 & 0.811 & 2 & 51.5 & 0.29 & 0.750 \\
\hline
\end{tabular}

Results for 2008 and 2009 analyzed separately. Num DF and Den DF abbreviations indicate numerator and denominator degrees of freedom, respectively.

summed over all traps (JMP statistical package, version 8, SAS Institute 2009). Analyses were carried out for the 2008 and 2009 field seasons separately.

\section{Results}

Male, mated female, and unmated female grape berry moth were captured on panel traps during the 2008 and 2009 field seasons. In total, 131 males, 81 mated females, and 25 unmated females were collected from 36 panel traps in 2008 (all treatments combined) and 104 males, 148 mated females and nine unmated females were collected from 32 traps in the 2009 field season. Because the majority of females captured were mated ( 81 out of 106 or $76 \%$ in 2008,148 out of 157 or $94 \%$ in 2009 ) we combined unmated and mated females for subsequent analyses. In 2008, there was a significant effect of type of lure on total female grape berry moth captured on panel traps (Table 2; Fig. 1). Averaged across season and location, the 7-component lure trapped significantly more female grape berry moth (approximately triple) than control traps (contrast "control" versus "7-component lure"; $\mathrm{F}_{1,24.2}=7.23, P=0.01$ ). While we captured an average of twice as many females on traps baited with the 13-component lure compared with control traps, this was not statistically different $\left(\mathrm{F}_{1,24.2}=1.46, P=0.24\right)$. No statistical differences were found between the 7-component lure and the 13-component lure $\left(\mathrm{F}_{1,24.2}=2.19\right.$, $P=0.15)$. There were no significant interactions between the lure treatment and other independent variables. Site, by itself, did not explain a significant amount of variation in number of females on panel traps in 2008, although a two-way (site and season) and a three-way interaction (site by season by location) were significant (Table 2). There was a significant overall main effect of location and season as well their interaction and the three-way interaction noted above (Table 2). For the Cayuga White block, approximately the same number of females were captured at the forest edge and vineyard edge early $\left(\mathrm{F}_{1,24}=0.53, P=0.73\right)$ and the mid-part of the season $\left(\mathrm{F}_{1,24}=1.77, P=0.20\right)$, but more females were captured in the vineyard edge relative to the forest edge by the end of the season $\left(\mathrm{F}_{1,24}=28.41\right.$, $P<0.001$, Fig. 1). For the Niagara block, no differences were seen between the forest and vineyard edges at the early, middle or late part of the season, although the trend was for more moths captured in the vineyard as the season progressed.

Similar results were obtained for female grape berry moth in 2009 with twice as many captured on traps with the plant lure relative to control (Table 2; Fig. 2). Differences between the synthetic host lure and control were most apparent toward the end of the season in the vineyard traps, hence the significant interaction between lure and season and lure, season and location (Table 2).

Approximately the same number of females were captured in the forest edge and vineyard edge early in the season (averaged across site) and more were captured in the vineyard late in the season $\left(\mathrm{F}_{1,38.8}=\right.$ 104.24, $P<0.001$, Table 2; Fig. 2).

The number of male grape berry moth captured on panel traps was significantly greater for traps baited with host plant lures compared with the control traps in the 2008 field season (Table 3; Fig. 3). Approximately three times as many males were captured on traps baited with the 13-component lure $\left(\mathrm{F}_{1,32.1}=11.56, P=0.002\right)$ or 7 -component lure $\left(\mathrm{F}_{1,32.1}=7.51, P=0.01\right)$ than control traps. There was no difference between numbers captured on 7-component and 13-component traps $\left(\mathrm{F}_{1,32.1}=\right.$ $0.44, P=0.51)$. Differences in males captured on panel traps between synthetic host lures and control traps were greatest early in the season, but became statistically insignificant by late in the season, hence the significant interaction between lure and season (Table 3; Fig. 3). More males were captured in the 

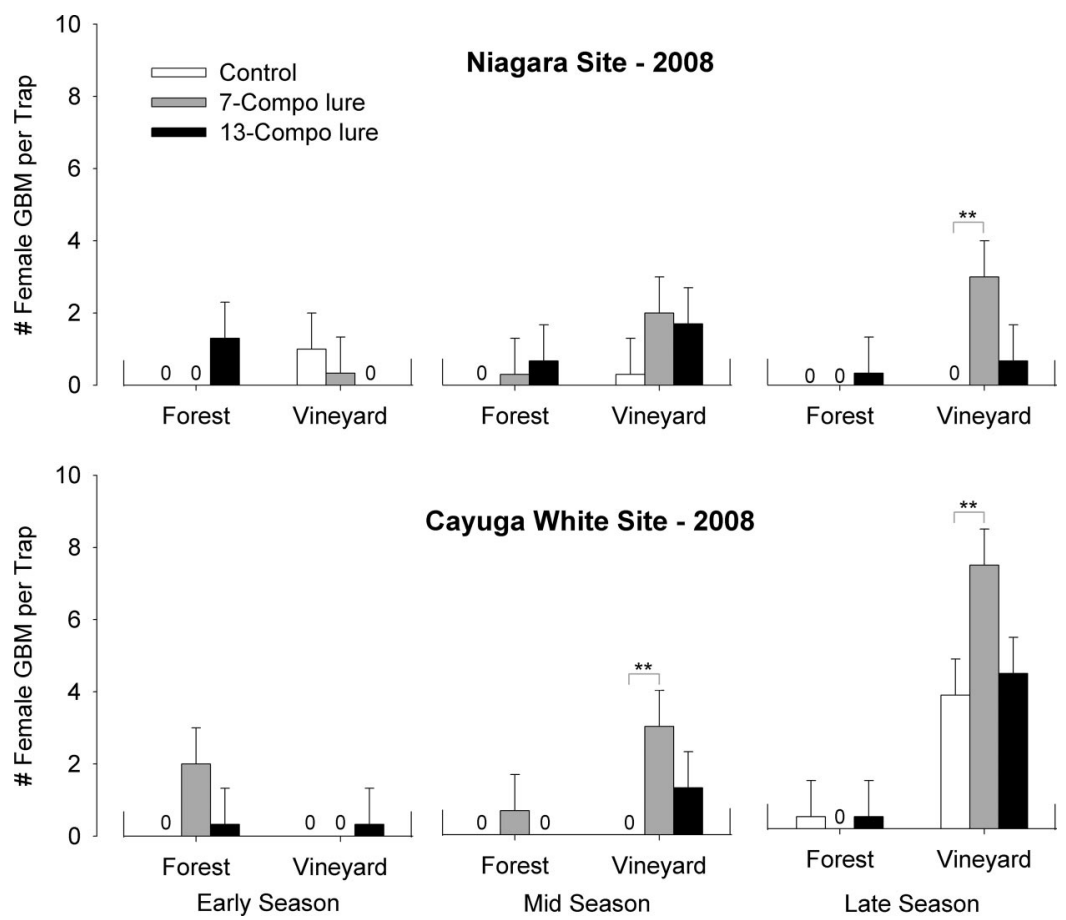

Fig. 1. Mean total grape berry moth females \pm SEM captured per panel trap baited with either host plant-based lures (13-component [black bar] or 7-component [gray bar] blends, see Table 1) or hexane control [white bar] in Niagara and Cayuga White vineyard blocks for traps located on the forest edge and vineyard edge during the early, middle and late parts of the 2008 field season. The effect of a specific lure at a specific site, location and season combination was compared with control by using contrast statements in SAS Proc Mixed. Statistical differences between lure treatments and control at the $P<0.05$ level indicated by $* *$ and at the $P<0.1$ level indicated by $*$.

forest edge early in the season $\left(\mathrm{F}_{1,71.5}=17.39, P<\right.$ $0.001)$, but this pattern was reversed late in the season $\left(\mathrm{F}_{1,71.5}=10.18, P=0.002\right.$, Fig. 3). Similar results for males captured on panel traps were obtained in 2009 with the exception that we observed a significant main effect of trap location and season, which was not the case for 2008 (Table 3; Fig. 4). We did not detect any statistically significant differences because of site for males on panel traps for either 2008 or 2009.

The ratio between male and female grape berry moth captured on panel traps varied over the season, ranging from a male bias in the early season $(\approx 3.5$ males per female captured on panel traps baited with synthetic host lure in 2008 and 1.3 males per female in 2009 ) to a more even ratio toward the middle (2008: 1.1 males per female, 2009: 1.0 males per female) and a bias to females during the later part of the season (2008: 0.7 males per female, 2009: 0.4 males per female).

In 2008 a total of 1,931 moths were collected from 12 pheromone traps, whereas in 2009 we counted 1,929 from eight traps. There was a significant effect of season in both years, with more males being captured in the early part of the season compared with the mid and late parts. Overall, more males were collected at the Niagara site than at the Cayuga White site in 2009 but not 2008 (Table 4). There also was a significant interaction between site and season for 2009 with more males being captured in the Niagara site early compared with the Cayuga White site (mean total of 222 per trap verses 74 ) and the reverse late (46 per trap verses 96). As expected, more males were collected from pheromone traps located in the forest edge compared with the vineyard early in the season (2008: mean total per forest edge trap $=267$, mean total per vineyard trap $=116 ; 2009$ : forest trap $=197$, vineyard trap $=99)$, with the opposite pattern developing by mid season (2008: mean total per forest trap $=9$, mean total per vineyard trap $=25 ; 2009$ : forest trap $=12$, vineyard trap $=33$ ) as indicated by the significant interaction between location and season for both field seasons (Table 4).

Using total numbers from all traps by week, males captured in pheromone traps was not a good predictor of females in panel traps in either field season (2008: $\mathrm{F}_{1,34}=1.45, P=0.24, \mathrm{r}=-0.20 ; 2009: \mathrm{F}_{1,34}=0.12, P=$ $0.73, r=-0.06)$. In contrast, there was a significant positive relationship between males captured in panel traps and females in panel traps $\left(2008: \mathrm{F}_{1.34}=6.30, P=\right.$ $\left.0.017, r=0.40 ; 2009: \mathrm{F}_{1,34}=25.9, P<0.001, r=0.66\right)$. The relationship between males captured in pheromone traps and on panel traps was significantly positive in 2008 but unrelated in 2009 (2008: $\mathrm{F}_{1,34}=4.08$, $\left.P=0.05, r=0.32,2009: \mathrm{F}_{1,34}=1.37, P=0.25, r=0.19\right)$. 

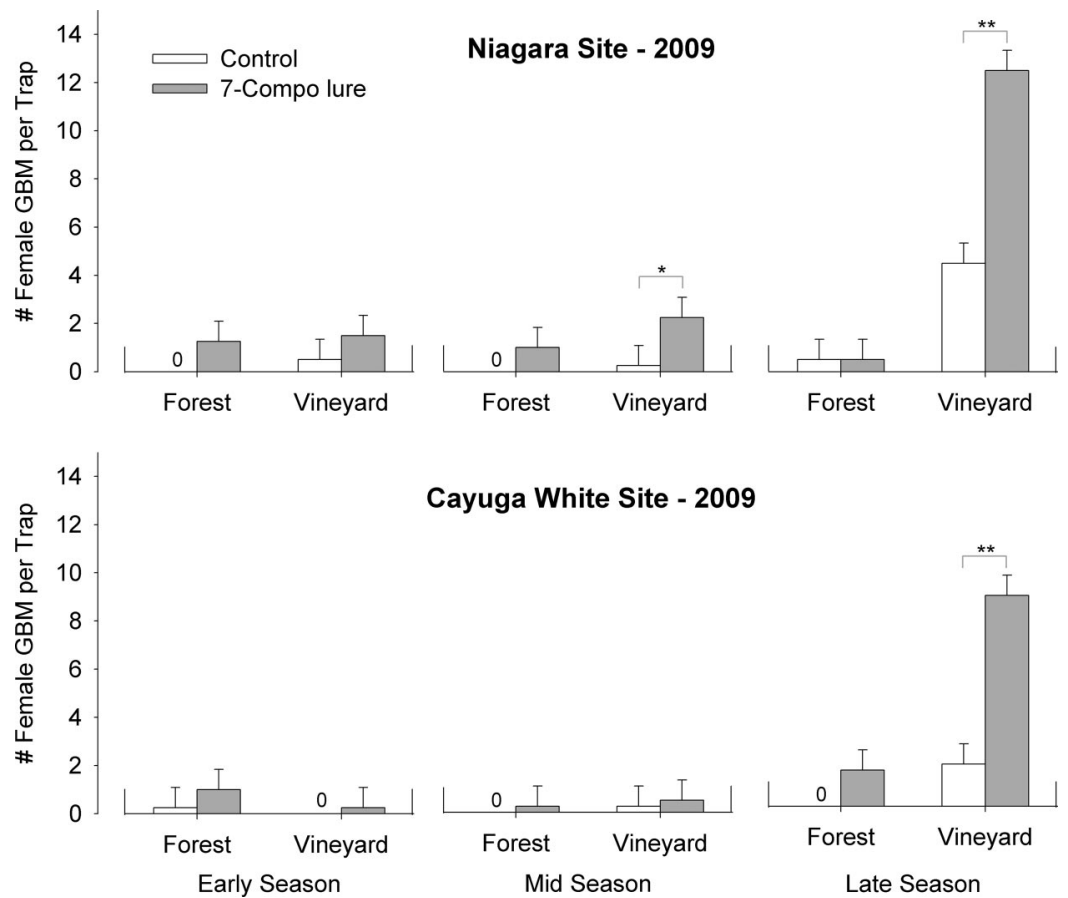

Cayuga White Site - 2009

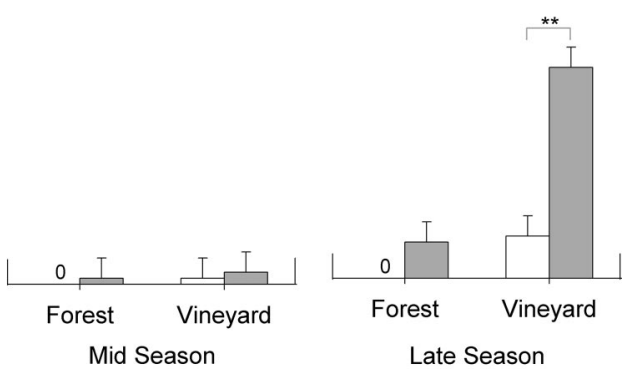

Fig. 2. Mean total grape berry moth females \pm SEM captured per panel trap baited with either host plant-based lure (7-component blend [gray bar], see Table 1) or hexane control [white bar] in Niagara and Cayuga White vineyard blocks for traps located on the forest edge and vineyard edge during the early, middle and late parts of the 2009 field season. The effect of a specific lure at a specific site, location and season combination was compared with control by using contrast statements in SAS Proc Mixed. Statistical differences between lure treatments and control at the $P<0.05$ level indicted by ** and at the $P<0.1$ level indicated by *.

Combining male and female grape berry moth captured on panel traps (all treatments) and plotting numbers against week during the field season shows three periods of activity: the spring flight adults from overwintered pupae, the second, mid-season flight and a late-season flight. This was most evident for 2008 field season, in which the mid-season flight encom- passes two peaks occurring fairly close in time (Fig. 5A); less so for 2009, especially the second and third flights (Fig. 5C). This is in contrast to the lack of evidence of the second flight with males captured in pheromone traps (Figs. 5B and 5D). Peak number of captured male and female moths in panel traps in 2008 occurred during the week of 9 June, then 14 July

Table 3. Mixed model repeated measures ANOVA results for total no. of males collected on panel traps at two vineyard plantings in central New York for 2008 and 2009 as affected by Site, Location (forest edge, vineyard edge), Lure (control, 7-C blend, 13 -C blend in 2008 and control and 7-C blend in 2009), Season (early, middle or late) and interactions

\begin{tabular}{|c|c|c|c|c|c|c|c|c|}
\hline \multirow{2}{*}{ Effect } & \multicolumn{4}{|c|}{2008} & \multicolumn{4}{|c|}{2009} \\
\hline & Num DF & Den DF & $\mathrm{F}$ & $\mathrm{P}$ & Num DF & Den DF & $\mathrm{F}$ & $\mathrm{P}$ \\
\hline Site & 1 & 32.1 & 0.11 & 0.737 & 1 & 29.3 & 2.73 & 0.109 \\
\hline Location & 1 & 32.1 & 0.55 & 0.462 & 1 & 29.3 & 5.08 & 0.032 \\
\hline Lure & 2 & 32.1 & 6.49 & 0.004 & 1 & 29.3 & 9.04 & 0.005 \\
\hline Lure*location & 2 & 32.1 & 2.75 & 0.079 & 1 & 29.3 & 0.56 & 0.458 \\
\hline Site*location & 1 & 32.1 & 2.42 & 0.129 & 1 & 29.3 & 3.25 & 0.081 \\
\hline Site*lure & 2 & 32.1 & 0.17 & 0.845 & 1 & 29.3 & 0.56 & 0.458 \\
\hline Lure* site $^{*}$ location & 2 & 32.1 & 0.44 & 0.645 & 1 & 29.3 & 1.45 & 0.239 \\
\hline Season & 2 & 50.3 & 0.63 & 0.539 & 2 & 49.0 & 6.17 & 0.004 \\
\hline Season*location & 2 & 50.3 & 14.57 & $<0.001$ & 2 & 49.0 & 19.94 & $<0.001$ \\
\hline Season*site & 2 & 50.3 & 0.90 & 0.412 & 2 & 49.0 & 1.05 & 0.357 \\
\hline Season*lure & 4 & 51.5 & 4.21 & 0.005 & 2 & 51.5 & 12.88 & $<0.001$ \\
\hline Season*site*location & 2 & 50.3 & 0.18 & 0.834 & 2 & 49.0 & 0.90 & 0.412 \\
\hline Season*lure*location & 4 & 51.5 & 1.48 & 0.221 & 2 & 49.0 & 1.17 & 0.319 \\
\hline Season*lure*site & 4 & 51.5 & 0.24 & 0.913 & 2 & 49.0 & 0.80 & 0.455 \\
\hline Season*lure*site*location & 4 & 51.5 & 0.12 & 0.976 & 2 & 49.0 & 0.42 & 0.660 \\
\hline
\end{tabular}

Results for 2008 and 2009 analyzed separately. Num DF and Den DF abbreviations indicate numerator and denominator degrees of freedom, respectively. 

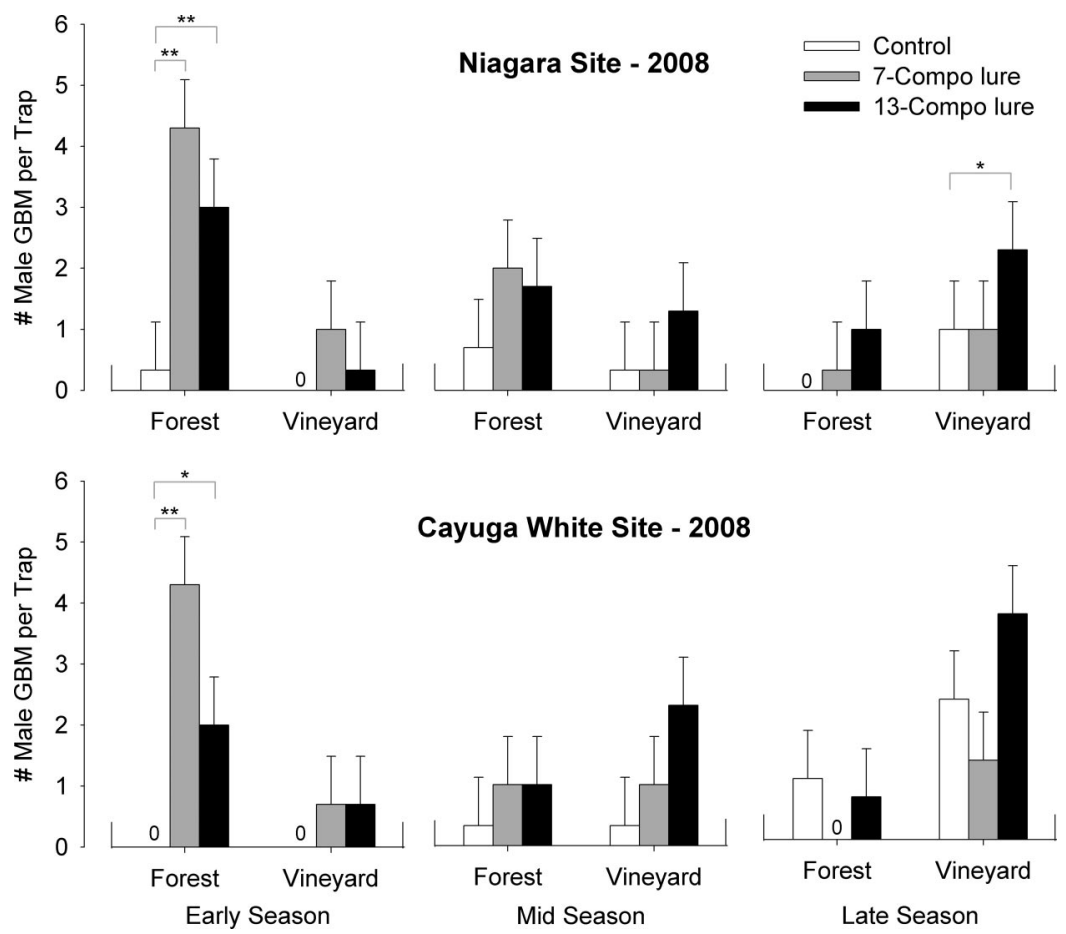

Fig. 3. Mean total grape berry moth males \pm SEM captured per panel trap baited with either host plant-based lures (13-component [black bar] or 7-component [gray bar] blends, see Table 1) or hexane control [white bar] in Niagara and Cayuga White vineyard blocks for traps located on the forest edge and vineyard edge during the early, middle and late parts of the 2008 field season. The effect of a specific lure at a specific site, location and season combination was compared with control by using contrast statements in SAS Proc Mixed. Statistical differences between lure treatment and control at the $P<$ 0.05 level indicted by $* *$ and at the $P<0.1$ level indicated by $*$.

(assuming the two middle peaks in Fig. 5A are part of the same flight), and a third peak on 25 August. The peak number of captured males in pheromone traps occurred during the week of 26 May for first flight, no clear peak for the middle of the season but possibly 28 July, and 25 August for the third peak. In 2009, the first peak in captured adults in panel traps occurred between 29 May and 14 June, with no clear second peak until 27 July, followed by a final peak on 1 September. For males in 2009 there was a clear first peak near 1 June, and then no clear second peak until perhaps 6 August, followed by a third peak on 19 August and a possible fourth peak on 8 September.

The number of male and female grape berry moth moths captured on panel traps baited with host-based lures tended to be low compared with males captured in pheromone-baited wing traps, especially early in the season. For example, in the spring of 2008 the average number of males caught in pheromone traps was, at its peak, $56(\mathrm{SE}=18.1) \mathrm{males} / \mathrm{trap} / \mathrm{wk} \mathrm{com}-$ pared with an average of $0.8(\mathrm{SE}=0.6)$ males + females/panel trap/wk for the 13-component blend and 1.3 $(\mathrm{SE}=0.6)$ males + females/panel trap/wk for the 7-component blend. At the mid-season peak in 2008 males captured in pheromone traps were much lower relative to the spring peak (mean $=3.9$ males/ trap/wk, $\mathrm{SE}=0.7$ ), but were still several times greater than total males and females captured on panel traps at the mid-season peak (mean for 13-component lure $=0.9$ per trap $/ \mathrm{wk}, \mathrm{SE}=0.3$; mean for 7-component lure $=1.2$ per trap $/ w k, S E=0.3)$. At the lateseason peak in 2008 the mean number of males captured in pheromone traps was $8.6(\mathrm{SE}=2.7)$ males/ trap/wk compared with 0.9 males + females/panel trap/wk $(\mathrm{SE}=0.3)$ for the 13-component lure and 0.8 males + females/panel trap/wk $(\mathrm{SE}=0.3)$ for the 7-component lure.

\section{Discussion}

Previous research on P. viteana identified a number of relatively common volatile compounds produced by grapes that were active in attracting female grape berry moth. This work was mostly based on electrophysiological and behavioral studies conducted in the laboratory (Cha et al. 2008a,b). In the current study we demonstrated in a commercial vineyard over two field seasons that traps baited with lures loaded with blends of these key volatile compounds captured significantly more female grape berry moth than control traps. Although it has been well established that female moths use host volatiles for host location (Visser 1986), there are relatively few cases where the essential compounds have been identified and successfully used under field conditions to monitor female phenology and spatial and temporal distribution. Codling 

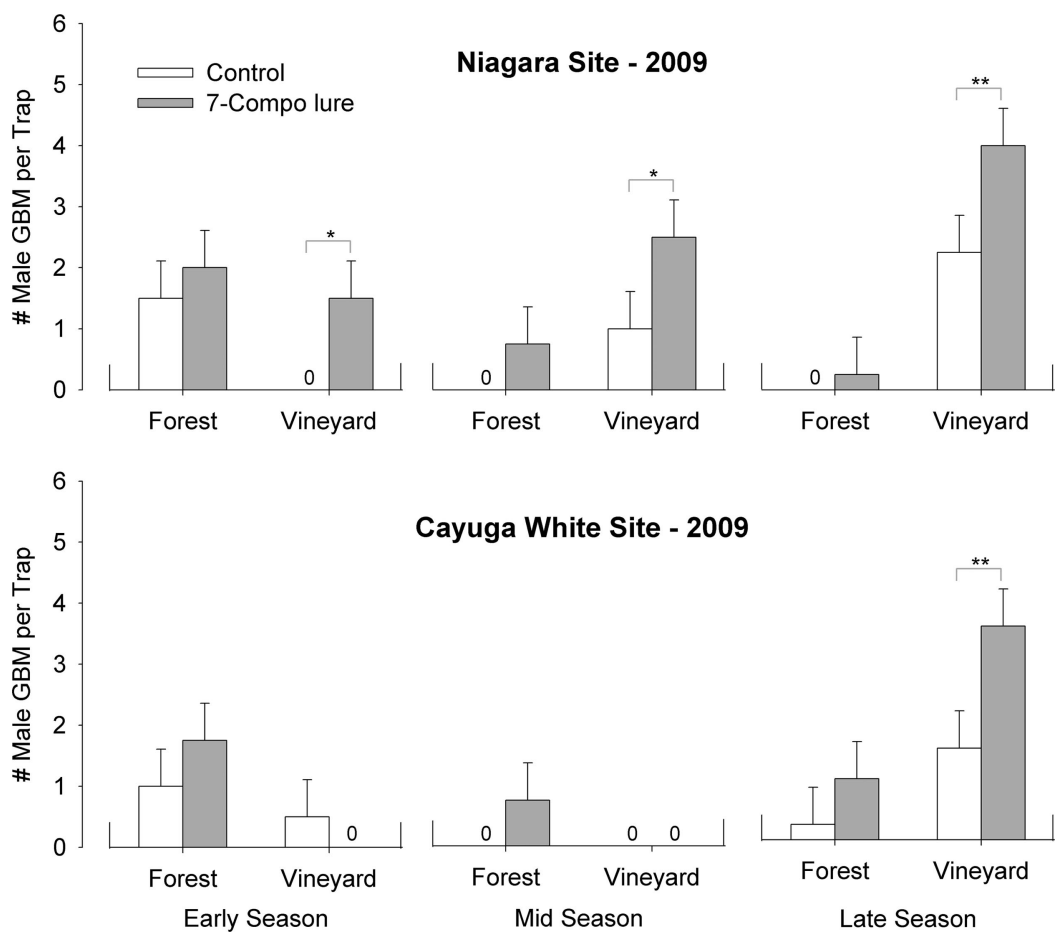

Fig. 4. Mean total grape berry moth males \pm SEM captured per panel trap baited with either host plant-based lure (7-component blend [gray bar], see Table 1) or hexane control [white bar] in Niagara and Cayuga White vineyard blocks for traps located on the forest edge and vineyard edge during the early, middle and late parts of the 2009 field season. The effect of a specific lure at a specific site, location and season combination was compared with control by using contrast statements in SAS Proc Mixed. Statistical differences between lure treatment and control at the $P<0.05$ level indicted by ** and at the $P<0.1$ level indicated by *.

moth, another tortriciid and major pest of fruit crops, is perhaps the best example where a host derived kairomone [ $(E, Z)$-2,4-decadieonoate] from pear has been used in North America, Europe, and Australia to monitor moths in the field, mostly in research mode (Light et al. 2001, Ioriatti et al. 2003, Il'chev 2004, Knight and Light 2005a,b). Schmidt et al. (2007) demonstrated field level activity of the pear ester not only for codling moth but also several other Tortricid species. In another well-studied system, the essential volatiles used by the European berry moth Lobesia botrana, also a blend of common plant volatiles, have been identified through a process quite similar to one used for P. viteana (Tasin et al. 2005; Tasin et al. 2006a,b; Tasin et al. 2007). To date field trials for $L$. botrana have been limited to large enclosure experiments where traps baited with the synthetic host lure captured significantly more female moths than control traps (Anfora et al. 2009).

We found significantly more male grape berry moth also were captured on panel traps baited with synthetic host plant lures compared with control traps in this study suggesting that males use at least some of the same host volatiles as females. Male codling moth also

Table 4. Mixed model repeated measures ANOVA results for total no. of males collected on pheromone traps at two vineyard plantings in central New York for 2008 and 2009 as affected by Site, Location (forest edge, vineyard edge), Season (early, middle or late) and interactions

\begin{tabular}{|c|c|c|c|c|c|c|c|c|}
\hline \multirow{2}{*}{ Effect } & \multicolumn{4}{|c|}{2008} & \multicolumn{4}{|c|}{2009} \\
\hline & Num DF & Den DF & $\mathrm{F}$ & $\mathrm{P}$ & Num DF & Den DF & $\mathrm{F}$ & $\mathrm{P}$ \\
\hline Site & 1 & 3.62 & 0.46 & 0.541 & 1 & 4.66 & 6.68 & 0.053 \\
\hline Location & 1 & 3.62 & 2.84 & 0.174 & 1 & 4.66 & 0.42 & 0.549 \\
\hline Site*location & 1 & 3.62 & 0.01 & 0.947 & 1 & 4.66 & 0.83 & 0.407 \\
\hline Season & 2 & 6.98 & 46.90 & $<0.001$ & 2 & 8.32 & 71.57 & $<0.001$ \\
\hline Season*site & 2 & 6.98 & 0.84 & 0.470 & 2 & 8.32 & 72.96 & $<0.001$ \\
\hline Season*location & 2 & 6.98 & 15.44 & 0.003 & 2 & 8.32 & 40.71 & $<0.001$ \\
\hline Season*site*location & 2 & 6.98 & 0.18 & 0.834 & 2 & 8.32 & 0.67 & 0.539 \\
\hline
\end{tabular}

Results for 2008 and 2009 analyzed separately. Num DF and Den DF abbreviations indicate numerator and denominator degrees of freedom, respectively. 

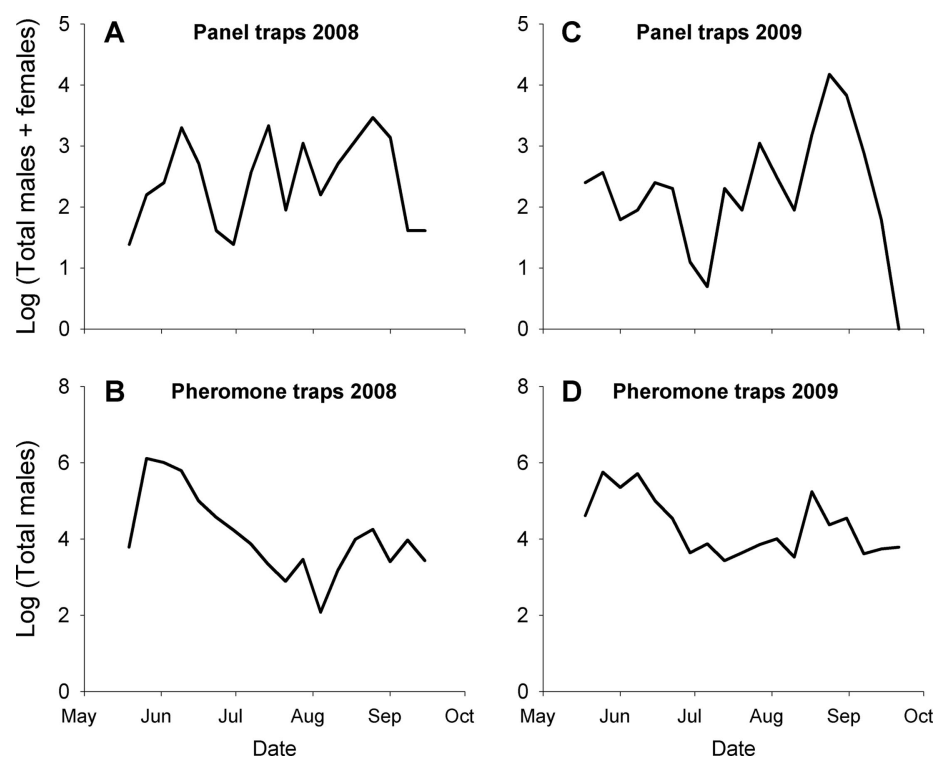

Fig. 5. Mean total number (log transformed) of grape berry moth captured during the field season for 2008 and 2009 . A. Males and females captured on panel traps (combining data from traps with host plant based lures and hexane control traps) in 2008. B. Males captured in pheromone-baited traps in 2008. C. Males and females captured on panel traps (combining traps with host plant based lure and hexane control traps) in 2009. D. Males captured in pheromone-baited traps in 2009.

is captured in traps baited with the pear ester kairomone under field conditions (Light et al. 2001, Ioriatti et al. 2003, Yang et al. 2004). In contrast, in flighttunnel trials male European berry moth did not orient to grapes or other grape tissue whereas females did (Masante-Roca et al. 2007). However, there is a growing body of evidence that male moths of a significant number of species are able to perceive and respond to host plant volatiles and in some cases, the addition of plant volatile cues with sex pheromone can result in increased capture of males (Light et al. 1993, Landolt and Phillips 1997, Yang et al. 2004, Schmidt-Büsser et al. 2009 but see Trimble and El-Sayed 2005). Indeed, a more recent study showed that male L. botrana oriented to their host plant volatiles (Von Arx et al. 2011). The potential of improving the usefulness of pheromone-baited traps for grape berry moth by the addition of host plant volatiles is worth further investigation.

The pattern of capturing more grape berry moth males in pheromone-baited traps compared with adult moths in host odor baited traps has been observed for codling moth and some other tortricid moths, although during some time periods and/or management practices the pattern is reversed (Light et al. 2001, Ioriatti et al. 2003, Knight and Light 2005a, Trimble and El-Sayed 2005, Schmidt et al. 2007).

The ratio between male and female codling moth captured in traps baited with pear ester is variable as was the case for grape berry moth. Some studies have found a more or less even ratio (Light et al. 2001, Knight and Light 2005a) whereas others have found a modest to strong male bias, at least for some flights (Ioriatti et al. 2003, Trimble and El-Sayed 2005, Schmidt et al. 2007). Reasons for seasonal variation in sex ratio in kairomone-baited traps are not clear but likely involve multiple factors, such at release rate of attractants, trap design, and trap placement (Ioriatti et al. 2003, Knight and Light 2005b).

The use of pheromone traps to determine grape berry moth flight phenology, based on the capture of males, can be problematic, especially later in the growing season (Hoffman et al. 1992, Botero-Garcés and Isaacs 2003, Teixeira et al. 2009). This is highlighted by our results in which males captured in pheromone traps were not well correlated to females or males captured in panel traps. Interestingly, though, males and females captured on panel traps were significantly, positively correlated in both field seasons, similar to the captures of male and female codling moth in pear ester-baited traps (Light et al. 2001, Trimble and El-Sayed 2005, Knight and Light 2005a). On a practical level, if host plant based lures were to be used commercially it may not be necessary to distinguish between males and females.

A large peak in males captured in pheromone traps for the spring flight followed by much lower levels later in the season, often without any clear peaks, commonly has been observed for grape berry moth (Teixeira et al. 2009 and references therein). It had been assumed that grape berry moth males are protandrous and emerge from overwintering diapause before females. Data on developmental rates do indicate slightly faster development in males than females (Tobin et al. 2001), although it is a relatively small difference. Moreover, we did not observe earlier capture of males than females on panel traps. Overall, we did not observe a close correlation between males captured in pheromone traps and males or females captured on panel traps. This is in contrast to codling 
moth where the pattern (seasonal peaks) is comparable between captured males in pheromone traps and males and females in traps baited with pear ester (Light et al. 2001, Knight and Light 2005a).

One possible explanation for poor correlation between male grape berry moth captured in pheromone traps and traps baited with synthetic host plant cues is that the 2-component sex pheromone lure used commercially for grape berry moth [ (Z-9-dodecenyl acetate and (Z)-11 tetradecenyl acetate in a 9:1 ratio ] is not a sufficiently close mimic to the actual femaleproduced pheromone. As such, early in the season, when females are not yet calling, the pheromonebaited traps are highly attractive to any males in the vicinity. However, when females begin calling they are more attractive to males than the synthetic pheromone. Hence, beyond the first flight, pheromone traps are relatively poor at tracking generational flights of grape berry moth. A study of the chemical constituents of the pheromone gland of grape berry moth revealed a number of small chain acetates and alcohols in addition to the two main components currently used in commercial lures (Witzgall et al. 2000). However, lures including some of these additional compounds did not increase the number of males captured in traps in field tests relative to the commercially used blend. It would be interesting to compare the efficacy of the commercial synthetic blend with tethered virgin females to further test how well the commercial blend competes over the season.

The pattern of captured males and females on panel traps provided a clearer picture of generation peaks than males in pheromone traps, especially for the middle and later part of the season. This was most evident in the 2008 where three peaks are clearly discernable on 3 June, 14 July and 25 August. The different generation flights of grape berry moth should be predictable based on temperature and degree-day accumulations. Based on growth chamber experiments Tobin et al. (2001) estimated a lower developmental threshold of $8.9^{\circ} \mathrm{C}$ and $\approx 410 \mathrm{DD}$ to go from egg to adult female. grape berry moth females typically do not begin laying eggs for 3- $4 \mathrm{~d}$ after eclosion in the lab at a constant $23^{\circ} \mathrm{C}$. Hence we estimated DD requirements to go from egg to egg-laying female at $\approx 450$. The interval between peaks in 2008 is very close to this amount (413 between 3 June and 16 July and 485 between 16 July and 25 August). For males in 2008 the interval between the first and second peak was 739 DD and 313 DD between second and third. For the 2009 field season generational peaks in males and females captured on panel traps were less distinct than in 2008, especially for the onset of the third flight. The DD accumulation between the first and second peak was $\approx 547 \mathrm{DD}$ and $424 \mathrm{DD}$ between the second and third peaks. Although panel trap data appears to better reflect intervals between peaks than pheromone trap data, there is still considerable variability. In part, this variability may be because of prolonged emergence of adults from winter diapause (Tobin et al. 2002).

Panel traps baited with the synthetic host plant lure captured significantly more male and female grape berry moth than control traps. Moreover, these traps provided a more accurate picture of seasonal flight patterns compared with traps baited with synthetic grape berry moth pheromone. Therefore, host plant based lures could be useful to improve the timing of pest management activities for grape berry moth such as determining optimal times to apply insecticides or to monitor for damage. However, two constraints limit their utility for commercial vineyard operations. First, the capture rates on a per trap basis were quite low in these field trials. Hence, it was necessary to deploy 15 or more traps per vineyard to capture a meaningful number of moths. The traps required nearly daily checking to ensure that specimen were in good shape for species and gender identification and oil-coated sheets needed replacement roughly once per week. Overall, the lure and panel trap design are currently neither efficient enough nor sufficiently easy to use to be commercially viable. Reasons for low capture efficiency could include design of the trap, loading and release rate of the lure, and probably most importantly, competition from the surrounding grape vines. Low capture rates also are observed for codling moth when the pear ester is used in pear orchards or later-season apple orchards (Light et al. 2001). These represent major challenges to fully exploiting host plant volatiles for monitoring and pest management of grape berry moth and other moth pests.

\section{Acknowledgments}

We appreciate the help of Michael Colizzi, Kevin Conley, Tim Robideau, Arianna Waheed, and Jessica Worden with data collection for these field trials. Pendleton Farms in Rushville, NY was kind enough to allow us to work in several of their commercial vineyards. The comments and suggestions from two anonymous reviewers improved the manuscript. The research was supported through grants from USDA NRI grant no. 2005-35302, USDA Viticultural Consortium East, and NY Wine and Grape Foundation.

\section{References Cited}

Alford, D.V.P.W. Carden, E. B. Dennis, H. J. Gould, and J.D.R. Vernon. 1979. Monitoring codling and tortrix moths in United Kingdom apple orchards using pheromone traps. Ann. Appl. Biol. 91: 165-178.

Anfora, G., M. Tasin, A. De Cristofaro, C. Ioriatti, and A. Lucchi. 2009. Synthetic grape volatiles attract mated Lobesia botrana females in laboratory and field bioassays. J. Chem. Ecol. 35: 1054-1062.

Bengtsson, M. G. Jaastad, G. Knudsen, S. Kobro, A. Bächman, E. Pettersson, and P. Witzgall. 2006. Plant volatiles mediate attraction to host and non-host plant in apple fruit moth, Argyresthia conjugella. Entomol. Exp. Appl. 118: $77-85$.

Botero-Garcés, N., and R. Isaacs. 2003. Distribution of grape berry moth, Endopiza viteana (Lepidoptera: Tortricidae), in natural and cultivated habitats. Environ. Entomol. 32 1187-1195.

Cha, D. H., S. P. Hesler, C. Moser, S. Nojima, C. E. Linn, W. L. Roelofs, and G. M. Loeb. 2008a. Flight tunnel responses of female grape berry moth (Paralobesia viteana) to host plants. J. Chem. Ecol. 34: 622-627.

Cha, D. H., S. Nojima, S. P. Hesler, A. Zhang, C. E. Linn, W. L. Roelofs, and G. Loeb. 2008b. Identification and field 
evaluation of grape shoot volatiles attractive to female grape berry moth (Paralobesia viteana). J. Chem. Ecol. 34: 1180-1189.

Cha, D. H., C. E. Linn, P.E.A. Teal, A. Zhang, W. L. Roelofs, and G. M. Loeb. 2011. Eavesdropping on plant volatiles by a specialist moth: significance of ratio and concentration. PLoS ONE. 6: e17033.

Cossé, A. A., J. J. Endris, J. G. Millar, and T. C. Baker. 1994. Identification of volatile compounds from fungus-infested date fruit that stimulate upwind flight in female Ectomyelois ceratoniae. Entomol. Exp. Appl. 72: 233-238.

Gleissner, B. D. 1943. Biology and control of the grape berry moth in the Erie grape belt. Penn. Agri. Exp. Stn. Bull. 451.

Gleissner, B. D., and H. N. Worthley. 1941. Evidence for a third brood of the grape berry moth, Polychrosis viteana Clemens, in the great lakes region. J. Econ. Entomol. 34: 426-431.

Glen, D. M., and P. Brian. 1982. Pheromone-trap catch in relation to the phenology of codling moth (Cydia pomonella). Ann. Appl. Biol. 101: 429-440.

Hern, A., and S. Dorn. 2004. A female-specific attractant for the codling moth, Cydia pomonella, from apple fruit volatiles. Naturwissenschaften 91: 77-80.

Hoffman, C. J. 1990. Development and validation of a risk assessment program for the management of grape berry moth, Endopiza viteana (Clemens), in New York state. $\mathrm{Ph}$. D. Dissertation, Cornell University, Ithaca, NY.

Hoffman, C. J., and T. J. Dennehy. 1989. Phenology, movement and within-field distribution of the grape berry moth, Endopiza viteana (Clemens) (Lepidoptera: Tortricidae), in new york vineyards. Can. Entomol. 121: 325335.

Hoffman, C. J., T. H. Dennehy, and J. P. Nyrop. 1992. Phenology, monitoring, and control decision components of the grape berry moth (Lepidoptera: Tortricidae) risk assessment program in New York. J. Econ. Entomol. 85: 2218-2227.

Howse, P., I. Stevens, and O. Jones. 1998. Insect pheromones and their use in pest management. Chapman \& Hall, NY.

Il'chev, A. L. 2004. First Australian trials of ethyl (2E,4Z)2,4-decadienoate for monitoring of female and male codling moth Cydia pomonella L. (Lepidoptera: Tortricidae) in pome fruit orchards. Gen. Appl. Entomol. 33: 15-20.

Ioriatti, C. F. Molinari, E. Pasqualini, A. de Cristofaro, S. Schmidt, and I. Espinha. 2003. The plant volatile attractant (E,Z) - 2,4-decadienoate (DA2313) for codling moth monitoring. Bollettino di Zoologia Agraria e di Bachicoltura., 35: 127-137.

JMP. Version 8. SAS Institute, Cary NC.

Knight, A. L. 2000. Monitoring codling moth (Lepidoptera: Tortricidae) with passive interception traps in sex pheromone-treated apple orchards. J. Econ. Entomol. 93: $1744-1751$.

Knight, A. L., and D. M. Light. 2005a. Seasonal flight patterns of codling moth (Lepidoptera: Tortricidae) monitored with pear ester and codlemone-baited traps in sex pheromone-treated apple orchards. Environ. Entomol. 34: $1028-1035$.

Knight, A. L., and D. M. Light. 2005b. Factors affecting the differential capture of male and female codling moth (Lepidoptera: Tortricidae) in traps baited with ethyl (E,Z)-2,4-decadienoate. Environ. Entomol. 34: 11611169 .

Landolt, P. J. 2000. New chemical attractants for trapping Lacanobia subjuncta, Mamestra configurata, and Xestia c-nigrum (Lepidoptera: Nocturidae). J. Econ. Entomol. 93: 101-106.
Landolt, P. J., and T. W. Phillips. 1997. Host plant influences on sex pheromone behavior of phytophagous insects. Annu. Rev. Entomol. 195: 853-864.

Li, S. Y., and S. M. Fitzpatrick. 1997. Monitoring obliquebanded leafroller (Lepidoptera: Tortricidae) larvae and adults on raspberries. Environ. Entomol. 26: 170-177.

Light, D. M., A. L. Knight, C. A. Henrick, D. Rajapaska, B. Lingren, J. C. Dickens, K. M. Reynolds, R. G. Buttery, G. Merrill, J. Roitman, and B. C. Campbell. 2001. A pearderived kairomone with pheromonal potency that attracts male and female codling moth, Cydia pomonella (L.). Naturwissenschaften 88: 333-338.

Light, D.M.A., L. Knight, R. G. Buttery, F. G. Zalom, R. E. Rice, J. C. Dickens, and E. B. Jang. 1993. Host-plant green-leaf volatiles synergize the synthetic sex pheromones of the corn earworm and codling moth (Lepidoptera). Chemoecology 4: 145-152.

Littell, R. C., G. A. Milliken, W. W. Stroup, and R. D. Wolfinger. 1996. SAS System for Mixed Models. SAS Institute, Cary, NC.

Luciani, M. A. 1987. The biology of the grape berry moth, Endopiza viteana Clemens (Lepidoptera: Tortricidae) in southern Ontario. M.S. thesis, University of Guelph, Guelph, ON.

Masante-Roca, I., S. Anton, L. Delbac, M. Dufour, and C. Gadenne. 2007. Attraction of the grapevine moth to host and non-host plant parts in the wind tunnel: effects of plant phenology, sex, and mating status. Entomol. Exp. Appl. 122: 239-245.

Metcalf, R. L., and E. R. Metcalf. 1992. Plant kairomones in insect ecology and control. Chapman \& Hall, London, United Kingdom.

Morewood, P., G. Gries, J. Liska, P. Kapitola, D. Häussler, K. Möller, and H. Bogenshutz. 2000. Towards pheromonebased monitoring of num moth, Lymantira monacha $(\mathrm{L})$ (Lepl, Lymantridae) populations. J. Appl. Entomol. 124: $77-85$.

Nagarkatti, S., P. C. Tobin, and M. C. Saunders. 2001. Diapause induction in the grape berry moth, Endopiza viteana (Clemens) (Lepidoptera: Tortricidae). Environ. Entomol. 30: 540-544.

Natale, D., L. Mattiacci, A. Hern, E. Pasqualini, and S. Dorn. 2003. Response of female Cydia molesta (Lepidoptera: Tortricidae) to plant derived volatiles. Bull. Entomol. Res. 93: 335-342.

Ramaswamy, S. B. 1988. Host finding by moths: sensory modalities and behaviours. J. Insect Physiol. 34: 235-249.

Ramaswamy, S. B., R. T. Cardé, and J. A. Witter. 1983. Relationships between catch in pheromone-baited traps and larval density of the spruce budworm, Choristoneura fumiferana (Lepidoptera: Tortricidae). Can. Entomol. 115: 1437-1443.

Ridgway, R. L., R. M. Silerstein, and M. N. Inscoe. 1990 Behavior-modifying chemicals for insect management. Marcel Dekker, Inc., NY.

Riedl, H., B. A. Croft, and A. J. Howitt. 1976. Forecasting codling moth phenology based on pheromone trap catches and physiological-time models. Can. Entomol. 108: $449-460$.

Rodriguez-Saona, C. R., and L. L. Stelinski. 2009. Behaviormediated strategies in FPM: theory and practice. In R. Peshin and A. K. Dhawan (eds.), Integrated Pest Management: Innovation-Development Process. Springer. pp. 263-315.

Roelofs, W. L., J. P. Tette, E. F. Tascheberg, and A. Comeau. 1971. Sex pheromone of the grape berry moth: Identification by classical and electroantennogram methods, and field tests. J. Insect Physiol. 17: 2235-2243. 
SAS Institute. 2009. The mixed model procedure, version 9.2. (http://www.sas.com).

Schmidt, S., G. Anfora, C. Ioriatti, G. Germinara, G. Rotundo, and A. de Cristofaro. 2007. Biological activity of ethyl (E,Z)-2,4-decadienoate on different tortricid species: electrophysiological responses and field tests. Environ. Entomol. 36: 1025-1031.

Schmidt-Büsser, D., M. Von Arx, and P. M. Guerin. 2009. Host plant volatiles serve to increase the response of male European grape berry moths, Eupoecilia ambiguella, to their sex pheromone. J. Comp. Physiol. A. 195: 853-864.

Shelton, A. M., and J. A. Wyman. 1979. Time of tuber infestation and relationships between pheromone catches of adult moths, foliar larval populations and tuber damage by the potato tuberworm. J. Econ. Entomol. 72: 599-601.

Taschenberg, E. F. 1945. The biology and control of the grape berry moth Polychrosis viteana (Clemens). Ph.D. dissertation, Cornell University, Ithaca, NY.

Tasin, M., G. Anfora, C. Ioriatti, S. Carlin, A. De Cristofaro, S. Schmidt, M. Bengtsson, G. Versini, and P. Witzgall. 2005. Antennal and behavioral responses of grapevine moth Lobesia botrana females to volatiles from grapevine. J. Chem. Ecol. 31: 77-87.

Tasin, M., A. C. Backman, M. Bengtsson, C. Ioriatti, and P. Witzgall. 2006a. Essential host plant cues in the grapevine moth. Naturwissenschaften 93: 141-144.

Tasin, M., A. C. Backman, M. Bengtsson, N. Varela, C. Ioriatti, and P. Witzgall. 2006b. Wind tunnel attraction of grapevine moth females, Lobesia botrana, to natural and artificial grape odour. Chemoecology 16: 87-92.

Tasin, M., A. Bäckman, M. Coracini, D. Casado, C. Ioriatti, and P. Witzgall. 2007. Synergism and redundancy in a plant volatile blend attracting grapevine moths. Phytochemistry 68: 203-209.

Teixeira, L. A., K. Mason, and R. Isaacs. 2009. Control of grape berry moth (Lepidoptera: Tortricidae) in relation to oviposition phenology. J. Econ. Entomol. 102: 692-698.

Tingle, F. C., and E. R. Mitchell. 1981. Relationships between pheromone trap catches of male tobacco budworm, larval infestation and damage levels in tobacco. J. Econ. Entomol. 74: 437-440.

Tobin, P. C., S. Nagarkatti, and M. C. Saunders. 2001. Modeling development in the grape berry moth, Endopiza viteana (Clemens) (Lepidoptera: Tortricidae). Environ. Entomol. 30: 692-699.

Tobin, P. C., S. Nagarkatti, and M. C. Saunders. 2002. Diapause maintenance and termination in grape berry moth (Lepidoptera: Tortricidae). Environ. Entomol. 31: 708 713.

Trimble, R. M., D. Pree, P. Vickers, and K. W. Ker. 1991. Potential of mating disruption using sex pheormone for controlling the grape berry moth, Endopiza viteana Clemens (Lepidoptera: Tortricidae), in Niagara peninsula, Ontario vineyards. Can. Entomol. 123: 451-460.

Trimble, R. M., and A. M. El-Sayed. 2005. Potential of ethyl (2E,4Z)-2,4-decadienoate for monitoring activity of codling moth (Lepidoptera: Tortricidae) in eastern North America apple orchards. Can. Entomol. 137: 110-116.

Van Steenwyk, R. A., E. R. Oatman, and J. A. Wyman. 1983. Density treatment level for tomato pinworm (Lepidoptera: Gelechiidae) based on pheromone trap catches. J. Econ. Entomol. 76: 440-445.

Vickers, R. A. and G.H.L. Rothschild. 1991. Use of sex pheromones for control of codling moth, pp. 339-354. In P. S. van der Geest and H. H. Evenhuis (eds.), Tortricid pests: their biology, natural enemies and control. Elsevier, Amsterdam, Netherlands.

Visser, J. H. 1986. Host odor perception in phytophagous insects. Annu. Rev. Entomol. 31: 121-144.

Von Arx, M., D. Schmidt-Busser, and P. M. Guerin. 2011. Host plant volatiles induce oriented flight behavior in male European grapevine moths, Lobesia botrana. J. Insect Physiol. doi:10.1016/j. jinsphys. 2011.06.010.

Wall, C. 1990. Principles of monitoring. In R. L. Ridgway, R. M. Silverstein, and M. N. Inscoe (eds.), Behaviormodifying chemicals for insect management. pp. 9-24. Marcel Dekker, Inc., NY.

Witzgall, P., M. Bengtsson, and R. M. Trimble. 2000. Sex pheromone of grape berry moth (Lepidoptera: Tortricidae). Environ Entomol. 29: 433-436.

Yang, Z., M. Bengstsson, and P. Witzgall. 2004. Host plant volatiles synergize response to sex pheromone in codling moth, Cydia pomonella. J. Chem. Ecol. 30: 619-629.

Received 29 September 2010; accepted 25 September 2011. 